This paper was accepted by Preventive Medicine. This is an author accepted version.

\title{
Causal evaluation of urban greenway retrofit: A longitudinal study on physical activity and sedentary behavior
}

Lawrence D. Frank, $\mathrm{PhD}^{\mathrm{a}}$, Andy Hong*, $\mathrm{PhD}^{\mathrm{b}}$, Victor D. Ngo, MA ${ }^{\mathrm{a}}$

${ }^{a}$ University of British Columbia

School of Population and Public Health

School of Community and Regional Planning

Room 360B - 2206 East Mall

Vancouver BC Canada V6T 1 Z3

${ }^{\mathrm{b}}$ University of Oxford

The George Institute for Global Health,

Nuffield Department of Women's \& Reproductive Health

Hayes House, 75 George Street

Oxford, OX1 2BQ, United Kingdom

*Corresponding Author

andyhong@gmail.com

andy.hong@georgeinstitute.ox.ac.uk 
This paper was accepted by Preventive Medicine. This is an author accepted version.

\title{
Causal evaluation of urban greenway retrofit: A longitudinal study on physical activity and sedentary behavior
}

\begin{abstract}
Studies of the built environment and physical activity (PA) have primarily been cross-sectional. Evidence on the causal impacts of transportation improvements on PA and sedentary behavior (SB) is lacking. This study assessed the effect of retrofitting an urban greenway on PA and SB in Vancouver, Canada. A sample of 524 participants (median age of $44 ; 57 \%$ female) were divided into experimental and control groups, and the effect of exposure to the greenway was examined by using different distance thresholds. Self-report measures of moderate-to-vigorous PA (MVPA) and SB were collected using the International Physical Activity Questionnaire (IPAQSF) before (baseline; 2012-2013) and after (follow-up; 2014-2015) construction of the ComoxHelmcken Greenway in 2013. Mixed-effects models estimated the impacts of greenway on MVPA and SB. For participants living near the greenway $(\leq 300 \mathrm{~m})$, the odds of achieving an average of 20 minutes of daily MVPA doubled $(\mathrm{OR}=2.00 ; 95 \% \mathrm{CI}=1.00,3.98)$ after the greenway's opening. The odds of being sedentary for more than 9 hours declined by $54 \%$ $(\mathrm{OR}=0.46 ; 95 \% \mathrm{CI}=0.25,0.85 ; p<0.01)$ after opening. PA benefits from the greenway declined with distance from 100 meters to 500 meters. Reduction in SB was lowest at 100 meters and greatest at 300 meters. Retrofitting an urban residential neighborhood through greenway intervention can be successful in promoting physical activity while reducing sedentary behavior. Recommendations for future longitudinal research include the use of objective PA measures, studying different neighborhood contexts, collecting more representative samples, and minimizing attrition.

\section{Highlights:}

- A pre-post evaluation of urban greenway on physical activity and sedentary behavior

- Participants near the greenway doubled their odds of achieving 20 minutes daily MVPA

- The odds of being sedentary for more than 9 hours halved for nearby residents

- Physical activity benefits declined with increasing distance from the greenway

- Retrofitting an urban greenway can be successful in promoting active lifestyle
\end{abstract}

\section{Keywords:}

greenway; retrofit; physical activity; sedentary behavior; longitudinal study; distance decay; active living; MVPA 
This paper was accepted by Preventive Medicine. This is an author accepted version.

\section{INTRODUCTION}

Physical inactivity and sedentary behavior are leading public health concerns in North America. Low levels of physical activity (PA) are associated with an increase in the risk of obesity (National Task Force on the Prevention and Treatment of Obesity, 2000; Office of the Surgeon General (US), 2001) and the development of other type II diabetes, stroke, cardiovascular diseases, and certain types of cancer (Warburton et al., 2006). Sedentary behavior (SB) is a separate risk factor for chronic diseases (Centers for Disease Control and Prevention (CDC), 2005; Colley et al., 2011; Frank et al., 2007; Sallis and Glanz, 2006). More than half of U.S. and $85 \%$ of Canadian adults do not meet recommended levels of PA (Centers for Disease Control and Prevention (CDC), 2005; Colley et al., 2011), and over half of U.S. adults spend approximately 7.7 hours daily engaged in sedentary behavior (SB). As a result, health promotion interventions that simultaneously address both physical inactivity and sedentary behavior can support chronic disease reduction (Centers for Disease Control and Prevention (CDC), 2005).

Recognizing the problems with physical inactivity, a growing body of research has focused on the role of active travel, such as walking and bicycling, in promoting physical activity (PA) (Donaire-Gonzalez et al., 2015; Mytton et al., 2016; Sahlqvist et al., 2012). More recently sedentary behavior has been explored as an independent risk factor from PA (Koster et al., 2012). There has been a shift in recommendations to include a reduction of SB in addition to increasing PA. Reallocating sedentary behavior time to more active behaviors has been linked to reduced risk of cardiovascular disease (Buman et al., 2014) and lower risk of obesity and cardiometabolic disease (Chastin et al., 2015). To promote PA and reduce SB through active travel, place-based interventions aimed at changing neighborhood-scale built environments and transportation infrastructure have gained wide support from urban planning researchers and practitioners (Frank et al., 2007; Handy et al., 2002; Sallis et al., 2016). Interventions in the built environment are of increasing interest to public health decision makers and practitioners as well because they impact everyone in a community at the population level rather than a selected subgroup who are exposed to a program (Fraser and Lock, 2011; Pucher et al., 2010). To this end, public health authorities and local governments are actively pursuing place-based interventions to increase overall PA while reducing sedentary behaviors (Brownson et al., 2008; Institute of Medicine (US) Committee on Health and Behavior: Research, Practice, and Policy, 2001; Sallis and Kerr, 2006; Waxman and World Health Assembly, 2004).

One such strategy to promote PA and reduce SB is investing in pedestrian and cycling improvements in locations with a connected street network and high levels of regional accessibility through transit and local access to destinations. Some communities are building dedicated active transportation facilities such as greenways close to individual's homes (Coutts, 2008; Gordon-Larsen et al., 2009; Sahlqvist et al., 2012; West and Shores, 2015). Urban greenways are linear landscaped traffic-calmed pathways that have a mix of bicycle facilities and other streetscape improvements that can knit major open spaces, parks, public facilities, and neighborhood centers together. Greenways re-appropriate road space from motor vehicles to active modes of travel, shifting the relative utility to be more favorable for walking and biking. Traffic-calmed, separated, and off-street facilities invite a greater diversity of potential bicycle users, particularly women and adults with children (Winters and Teschke, 2010). For this reason, the provision of safe and accessible active transportation infrastructure is believed to increase active travel behavior, and subsequently increase PA (Heath et al., 2006). 
This paper was accepted by Preventive Medicine. This is an author accepted version.

Although there is emerging evidence of SB impacts on health (Katzmarzyk, 2010), existing research on the health impacts of greenways is almost exclusively focused on PA promotion. This is troubling because greenways may not only provide health benefits by increasing PA but also reducing SB through increasing daily movements (Owen et al, 2012). Even with existing studies that examined PA, the results are mixed - some studies have reported positive PA impacts of greenways, whereas others have reported no effects (Evenson et al., 2005; Fitzhugh et al., 2010; Merom et al., 2003; West and Shores, 2011). In addition, the effect of greenways in terms of distance decay or diminishing impacts over space is not well understood. What is the area of impact of a greenway? How close to a greenway does someone need to be to receive more PA benefit, and how much benefit is there for someone close compared to someone else with similar characteristics further away (Duncan et al., 2016)?

Most studies of urban greenways cannot make causal inference because they typically rely on cross-sectional data. For this reason, longitudinal studies are currently a research priority to better establish and assess causal relationships between community design and physical health (Hunter et al., 2015; Sallis et al., 2009). Longitudinal designs also offer the ability to establish an ordered stimulus response relationship. They also control for residential self-selection present in transportation and health research, where a population's observed behavior is not only a function of people's residential built environment, but their attitudinal predispositions (Boone-Heinonen et al., 2011). Accounting for residential self-selection is not feasible through repeat crosssectional designs that employ two distinct samples at two different time points (Mokhtarian and Cao, 2008).

Our study addresses this gap by presenting findings from a natural experiment evaluation of retrofitting an urban greenway in downtown Vancouver to promote active travel and physical activity (PA) while reducing sedentary behavior (SB). This study has two objectives. First, it assesses the effect of the greenway retrofit on moderate-to-vigorous physical activity (MVPA) and sedentary behavior for residents living close to and further away from the greenway. Second, it assesses the effect of residential proximity (distance away from the greenway) on the MVPA and sedentary behavior outcomes.

\section{METHODS \\ Study Sample}

The study uses data from the Comox-Helmcken Greenway Study, a three-year longitudinal study that took place from 2012 to 2015. One of the primary aims of the study was to evaluate the impact of the Comox Greenway construction on PA and sedentary behaviors of residents. The Comox Greenway is a major active transportation corridor extending east-to-west through downtown Vancouver, with a particular aim of improving conditions for bicyclists of all ages and abilities (Figure 1). The two-kilometer route consists of a mix of cycling facilities and other streetscape improvements: one-way shared on-street with counterflow lanes (22\%); one-way protected (29\%); and two-way shared on-street (49\%). 

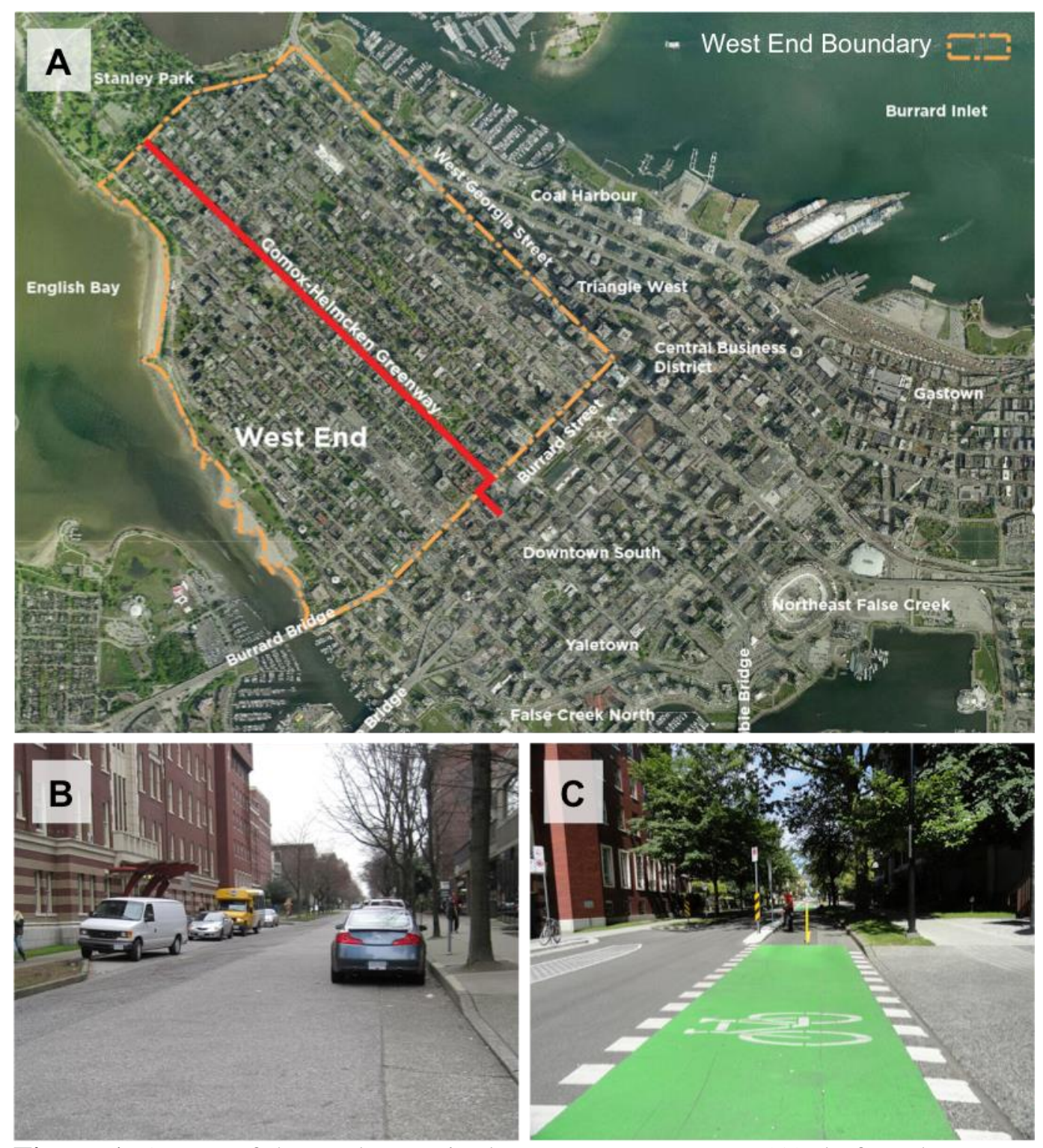

Figure 1. A map of the study area in downtown Vancouver (A); before the greenway intervention (B); after the greenway intervention (C) 
This paper was accepted by Preventive Medicine. This is an author accepted version.

More detailed sampling and data collection procedures are described elsewhere (Ngo et al., 2018). In brief, residents living approximately within one kilometer of the greenway were included in the study population. The study area is located in Vancouver's West End, a highdensity residential and commercial neighborhood. A random sample of household addresses were identified by Mustel Group, a third-party market research company, using the Canada Post address data file as the sampling frame. Invitation letters were sent out by mail from the City of Vancouver to potential participants. Residents who provided informed consent were recruited into the study if they had no plans to move outside the study area during the time of the study. No reference to the proposed greenway was provided to minimize participation bias.

A survey was conducted during the fall and winter for both pre- and post-periods to ensure consistent seasonal background conditions. The baseline period was from October 2012-March 2013. The greenway opened in June 2013, and a follow-up was conducted from October 2014March 2015. This period was selected to provide a conservative assessment of the greenway's effect on PA because bicycle volumes are typically lower during the fall and winter months compared to the summer (City of Vancouver, n.d.). Inclusion of fall and winter months also ensured that travel characteristics were stable throughout the study period (e.g., to avoid bias due to increased bicycling activities during summer).

Participants completed a questionnaire online with a hardcopy backup available. Incentives for participation included gift certificates and a prize draw to civic facilities ( $\$ 10$ and $\$ 1,000$ value respectively). A total of 1,744 mailings were sent out. For the baseline period, a total of 1,113 participants were recruited (63.8\% response rate). Participants were excluded from the study if they did not participate in the follow-up period $(n=556)$, did not complete the survey for the two survey days $(n=25)$, or were otherwise ineligible $(n=8)$. The final sample size for analysis was 524 participants (30.1\% response rate; $47.1 \%$ attrition rate). A sample size calculation was conducted showing that given a neighborhood population of 44,543 (City of Vancouver, n.d.)., $95 \%$ confidence level, and a 5\% margin of error, a minimum of 381 subjects needed to be analyzed. A participant drop-out analysis was conducted and with no statistically significant differences found across socio-demographic characteristics from the baseline sample to the final follow-up sample.

To define the experimental and control groups (operationalized as exposure to the greenway), a dummy variable was created using five distance thresholds measuring residential proximity to the greenway: 100, 200, 300, 400, and 500 meters (West and Shores, 2011). Note that our study uses multiple distance thresholds in response to earlier studies that used varying and inconsistent thresholds for evaluating active transportation facilities (Hunter et al., 2015). Graded measures of exposures, such as distance from the intervention, are an appropriate way to define comparison groups in natural experiments (Benton et al., 2017). To represent the base experimental condition, a threshold of 300 meters was selected based on two criteria. First, 300 meters is equal to two-and-a-half street blocks using the existing street grid before reaching a major commercial street. Beyond this distance, bicyclists have the option of choosing a more attractive existing offroad shared pedestrian and bicyclist pathway along the waterfront. Second, 300 meters provides a roughly equal sample size for the experimental and control groups. 
This paper was accepted by Preventive Medicine. This is an author accepted version.

\begin{abstract}
Measures
MVPA and sedentary behavior were assessed using the short form International Physical Activity Questionnaire (IPAQ-SF). The IPAQ measure has been shown to be a reliable and valid measure of physical activity (Craig et al, 2003), and has been used in several intervention studies (Christos et al., 2008; Chor et al., 2016). Following recommendations from a previous study (Bauman et al., 2009), a categorical reporting was used instead of a continuous measure to compensate for its high variance.
\end{abstract}

For MVPA, participants were asked if they had engaged in both utilitarian and recreational moderate and vigorous activity in the past seven days, covering only activities with a duration of at least 10 minutes. Participants were then identified as active if they achieved an average of 20 minutes daily of MVPA and inactive otherwise. For sedentary behavior, participants were asked how much time they spent sitting on a typical weekday. Participants were regarded as sedentary if they spent sitting more than or equal to 9 hours daily and non-sedentary otherwise. The 20 minutes/day MVPA and 9 hours/day sedentary behavior measures reflect an average daily rate based on the estimated total weekly activity across the seven days; subjects did not have to complete a minimum number of days of at least 20 minutes of activity for inclusion in the analysis. For the seven-day IPAQ reporting period, we found an effect prospectively when a threshold of 20 minutes per day of MVPA was used. Sensitivity of different time thresholds was tested for 25 minutes and 30 minutes for MVPA, which reflect recommended guidelines that adults engage in at least 150 minutes per week of MVPA (Colley et al., 2011), and 8 and 10 hours for sedentary behavior (see supplementary material).

Participants self-reported their age, gender (male $=1$, female $=0)$; ethnicity $(1=$ white, $0=$ nonwhite), employment status (employed $=1$, not employed $=2$ ), and educational attainment (completed post-secondary education $=1$, completed secondary education $=0$ ). Educational attainment was used as a proxy for annual household income to compensate for higher item nonresponse rate for income, which is common in most survey-based studies (Craig and McCann, 1978; Ting et al., 2010). The two variables were highly correlated (Pearson's $\chi^{2}=37.8$, $p<0.001$, Fisher's exact $p<0.001)$ and estimated model parameters were within range when substituting education with income. To determine residential proximity, a GIS street network file was obtained from the City of Vancouver Open Data Catalogue. The study area is notable as it is considered one of the most walkable neighborhood in the Vancouver region, characterized by a highly granular street network. Shortest Euclidean distance from the participants' home to the greenway was calculated using ArcGIS (version 10.1). There was little difference between the Euclidean and network distance due to the study location's street network context. Temperature data were retrieved from an Environment Canada weather monitoring station to adjust for seasonal and weather effects on active travel (Saneinejad et al., 2012). Daily mean temperature data were averaged over the seven-day IPAQ reporting period.

\title{
Statistical Analysis
}

Baseline differences in demographic covariates were compared across the experimental and control groups using two-tailed $t$-tests. Changes in demographic variables from baseline to follow-up were compared using paired t-tests. As the measures of MVPA and sedentary behavior did not follow a normal distribution, Wilcoxon signed rank tests and Pearson's chi-squared tests were performed from baseline to follow-up. 
This paper was accepted by Preventive Medicine. This is an author accepted version.

Mixed-effects logistic regression models with a random intercept for subjects were used to estimate the effect of greenway exposure on the primary outcome measures. The outcome measures were regressed with an interaction term (greenway exposure $\times$ time), allowing the model to estimate the outcome measures' change over time from the greenway intervention relative to a control (Twisk, 2013). The models were adjusted for socio-demographic and weather covariates during the baseline period. Significance levels were set at $p<0.05$. Participants missing the outcome measures ( $n=40$ for MVPA; $n=38$ for sedentary behavior) were not included in the models. There were no significant differences for the socio-demographic variables between the data with and without the missing outcome variables. The statistical analyses were performed with Stata (version 12).

\section{RESULTS}

Table 1 shows a descriptive summary of the sample using the 300-meter as the base experimental condition. The median age was 44 during the baseline, with participants ranging in age from 21 to 90 years. The median age in the experimental group was 45 years and 43 in the control group. The majority of the sample identified as female, with $55.3 \%$ in the experimental group and $59.0 \%$ in the control. There was a significant difference in ethnicity between the experimental (86.2\% white) and the control group (76.8\% white), $t=-2.7, p<0.01$. When compared to the entire West End neighborhood of the downtown Vancouver (sample population), our sample is older (median age of 38 years in the neighborhood) with a greater proportion of females ( $48 \%$ in the neighborhood) (City of Vancouver, n.d.). 
This paper was accepted by Preventive Medicine. This is an author accepted version.

Table 1. Descriptive characteristics of participants $(n=524)$

\begin{tabular}{|c|c|c|c|c|c|}
\hline & \multirow[t]{2}{*}{ Time } & \multicolumn{2}{|c|}{ Experimental $(n=239)$} & \multicolumn{2}{|l|}{ Control $(n=285)$} \\
\hline & & $\begin{array}{l}\text { Mean } \\
(95 \% \mathrm{CI})\end{array}$ & $n$ & $\begin{array}{l}\text { Mean } \\
(95 \% \mathrm{CI})\end{array}$ & $n$ \\
\hline Age & 1 & $46.2(44.3,48.1)$ & 239 & $44.7(43.0,46.4)$ & 285 \\
\hline Gender (\% Female) & 1 & $0.55(0.49,0.62)$ & 239 & $0.59(0.53,0.65)$ & 285 \\
\hline Ethnicity (\% White) $* *$ & 1 & $0.86(0.82,0.91)$ & 239 & $0.77(0.72,0.82)$ & 285 \\
\hline Employment status & 1 & $0.73(0.67,0.78)$ & 239 & $0.77(0.72,0.82)$ & 285 \\
\hline Post-secondary educational attainment $*$ & 1 & $0.72(0.67,0.78)$ & 239 & $0.78(0.73,0.83)$ & 285 \\
\hline \multirow[t]{2}{*}{ Number of household children } & 1 & $0.10(0.05,0.15)$ & 239 & $0.12(0.07,0.17)$ & 285 \\
\hline & 2 & $0.12(0.07,0.17)$ & 239 & $0.13(0.08,0.18)$ & 285 \\
\hline \multirow[t]{2}{*}{ Mean temperature $\left({ }^{\circ} \mathrm{C}\right)$} & 1 & $6.7(6.5,7.0)$ & 239 & $6.8(6.5,7.0)$ & 285 \\
\hline & 2 & $6.9(6.6,7.2)$ & 239 & $6.9(6.6,7.2)$ & 285 \\
\hline Average daily moderate-to-vigorous & 1 & $51.9(43.2,60.5)$ & 219 & $58.7(48.1,69.3)$ & 265 \\
\hline physical activity time (minutes) & 2 & $62.9(47.6,78.2)$ & 219 & $52.8(43.6,62.0)$ & 265 \\
\hline Met moderate-to-vigorous activity & 1 & $67.6(61.3,73.8)$ & 219 & $68.7(63.1,74.3)$ & 265 \\
\hline guidelines, $\geq 20 \mathrm{~min} /$ day (\%) & 2 & $69.4(63.3,75.6)$ & 219 & $60.8(54.8,66.7) *$ & 265 \\
\hline \multirow[t]{2}{*}{ Average daily sedentary time (minutes) } & 1 & $487.7(449.4,526.0)$ & 222 & $473.8(444.7,502.8)$ & 264 \\
\hline & 2 & $457.7(425.8,489.6)$ & 222 & $492.9(459.8,525.9)$ & 264 \\
\hline Accumulated excess sedentary time, & 1 & $45.9(39.3,52.6)$ & 222 & $36.7(30.9,42.6)$ & 264 \\
\hline$\geq 9$ hours/day $(\%) *$ & 2 & $33.3(27.1,39.6) * *$ & 222 & $37.9(32.0,43.8)$ & 264 \\
\hline
\end{tabular}

Note: Sample characteristics reported for participants living within 300 meters of the greenway. Significance for paired $t$-test, Wilcoxon signed rank tests, and Pearson's chi-squared test reported for time 1 (baseline) vs. time 2 (follow-up) (asterisk in time 2 row) and treatment vs. control during time 1 baseline (asterisk beside variable). 40 missing from MVPA measures (20 from treatment; 20 from control); 36 missing from sedentary behavior measures (15 from treatment; 21 from control) $p<0.05(*), p<0.01(* *), p<0.001(* * *)$ 
This paper was accepted by Preventive Medicine. This is an author accepted version.

In the experimental group, participants had an average of 51.9 minutes $(95 \% \mathrm{CI}=43.2,60.5)$ daily of MVPA during the baseline. After the opening of the greenway, there was a nonsignificant increase of $17.5 \%$ in terms of percentage change to 62.9 minutes $(95 \% \mathrm{CI}=47.6,78.2)$ of daily MVPA. The number of participants achieving the MVPA threshold of 20 minutes daily increased by $2.7 \%$ in terms of percentage change from a baseline of $67.6 \%(95 \% \mathrm{CI}=61.3,73.8)$ to $69.4 \%(95 \% \mathrm{CI}=63.3,75.6)$ after the opening of the greenway. For the control, participants had an average of 58.7 (95\% CI=48.1, 69.3) daily of MVPA during the baseline. After the opening of the greenway, there was a non-significant reduction of $10.1 \%$ to 52.8 minutes $(95 \%$ $\mathrm{CI}=43.6,62.0)$ daily of MVPA. Those meeting the MVPA threshold decreased by $11.5 \%$ from a baseline of $68.7 \%(95 \% \mathrm{CI}=63.1,74.3)$ to $60.8 \%(95 \% \mathrm{CI}=54.8,66.7)$ after opening.

In terms of sedentary behavior, participants in the experimental group had an average of 487.7 minutes $(95 \% \mathrm{CI}=449.4,526.0)$ daily of sedentary time, decreasing by $6.2 \%$ after the opening of the greenway to 457.7 minutes $(95 \% \mathrm{CI}=425.8,489.6)$ of sedentary time. For the experimental group, $45.9 \%(95 \% \mathrm{CI}=39.3,52.6)$ were sedentary for more than 9 hours daily during baseline, decreasing by $27.5 \%$ after opening to $33.3 \%$ (95\% $\mathrm{CI}=27.1,39.6)$. For the control group, participants had an average of 473.8 minutes $(95 \% \mathrm{CI}=444.7,502.8)$ of sedentary time during the baseline, increasing by $4 \%$ to 492.9 minutes $(95 \% \mathrm{CI}=459.8,525.9)$ of sedentary time after the greenway opening. There were $36.7 \%(95 \% \mathrm{CI}=30.9,42.6)$ of participants who were sedentary for more than 9 hours during baseline, increasing by 3.3\% after the greenway's opening to $37.9 \%$ (95\% CI=32.0, 43.8). The reduction in PA and increase in sedentary time observed in the control was attributed to an increase in amount of driving (Ngo et al., 2018).

Mixed-effects model results for MVPA and sedentary behavior using the 300-meter base experimental condition are reported in Table 3. In the adjusted model, the odds of achieving 20 minutes daily of MVPA increased by $100 \%(2.00 ; 95 \% \mathrm{CI}=1.00,3.98)$ after opening. This effect showed a declining trend with distance away from the greenway (see Figure 2). The highest effect size was observed at 100 meters $(2.04 ; 95 \% \mathrm{CI}=0.97,4.28)$ after opening. Participants living furthest away from the greenway at 400 and 500 meters had a lower effect size of 1.54 $(95 \% \mathrm{CI}=0.74,3.21)$ and $1.08(95 \% \mathrm{CI}=0.40,2.96)$ respectively after opening. 
This paper was accepted by Preventive Medicine. This is an author accepted version.

Table 2. Mixed-effects logistic models of moderate-to-vigorous physical activity and sedentary behavior

\begin{tabular}{|c|c|c|c|c|}
\hline & \multicolumn{2}{|c|}{$\begin{array}{l}\text { Moderate-to-Vigorous Physical } \\
\text { Activity ( } \geq 20 \mathrm{~min} / \text { day Threshold) }\end{array}$} & \multicolumn{2}{|c|}{$\begin{array}{l}\text { Sedentary Behavior } \\
\text { Time ( } \geq 9 \text { hours/day Threshold) }\end{array}$} \\
\hline & Unadjusted & Adjusted & Unadjusted & Adjusted \\
\hline Greenway exposure & $0.93(0.50,1.70)$ & $0.88(0.48,1.61)$ & $1.68(1.02,2.78)$ & $\begin{array}{l}1.72(1.04, \\
2.82)\end{array}$ \\
\hline Time & $0.57(0.36,0.91)$ & $0.58(0.36,0.92)$ & $1.07(0.71,1.61)$ & $\begin{array}{l}1.06(0.79, \\
1.60)\end{array}$ \\
\hline Greenway exposure $\times$ Time & $1.99(1.00,3.96)$ & $2.00(1.00,3.98)$ & $0.45(0.24,0.84)$ & $\begin{array}{l}0.46(0.25 \\
0.85)\end{array}$ \\
\hline AIC & 1174.96 & 1172.74 & 1262.11 & 1226.93 \\
\hline$n$ (Treatment) & 219 & & 222 & \\
\hline$n$ (Control) & 265 & & 264 & \\
\hline$N$ (Total) & 484 & & 486 & \\
\hline
\end{tabular}

Note: Odds ratio (95\% CI). "Greenway exposure" defined as participants living within 300 meters of the greenway. Covariates in final adjusted model: age, gender $($ male $=1$, female $=0$ ), ethnicity (white $=1$, non-white $=0$ ), employment status (employed full- or part-time $=1$, not employed $=0$ ), educational attainment (completed post-secondary education $=1$, completed secondary education $=0)$, number of household children, and mean temperature $\left({ }^{\circ} \mathrm{C}\right)$. 
This paper was accepted by Preventive Medicine. This is an author accepted version.

In terms of sedentary behavior, the model showed that the odds of being sedentary were reduced by $54 \%(0.46 ; 95 \% \mathrm{CI}=0.25,0.85)$ after opening. The distance effect exhibited an inverse relationship for sedentary behavior compared to MVPA (see Figure 2). At 100 meters, the odds of being sedentary were only reduced by $33 \%(0.67 ; 95 \% \mathrm{CI}=0.25,1.78)$. However, the reduction effect was greatest for those living at 300 meters, and at 500 meters $(0.48 ; 95 \%$ $\mathrm{CI}=0.19,1.22$ ). In other words, the sedentary behavior reduction benefit of the greenway appeared to be the lowest for those living closest.

\section{DISCUSSION}

This study found that retrofitting an urban greenway in a dense downtown Vancouver neighborhood resulted in an increase in MVPA and reduced sedentary behavior for those within 300 meters. These results are consistent with previous studies that report a positive correlation between active transportation facilities and increased PA (Buehler and Dill, 2016). The results bolster similar findings from previous cross-sectional studies by providing longitudinal evidence that the provision of active transportation facilities leads to an increase in PA and a reduction in sedentary behavior.

For evaluation of urban greenway interventions, the current study makes several important contributions. First, this is among the first published longitudinal studies examining the PA effects of a greenway, and among the first within a Canadian context (Hunter et al., 2015; Ottoni et al., 2016). The findings are aligned with the positive results of Western Europe and Australian-based studies compared to more mixed results of U.S.-based studies (Brown et al., 2016). Second, our study's follow-up period was two years from baseline compared to other studies that had less than a year of follow-up. A short follow-up period may be insufficient to detect lasting behavior change (Buehler and Dill, 2016; Dill et al., 2014). Third, our study provides a novel accounting of the potential confounding effect of weather and seasonal conditions, which are seldom included in PA and built environment research. Factors including temperatures, humidity, and precipitation have been shown to affect greenway usage (Burchfield et al., 2012).

Furthermore, our results found that the effects of urban greenway generally showed a declining trend as distance from the greenway increased. The MVPA benefit appeared to be greatest for residents living immediately adjacent to the greenway at 100 meters $(\mathrm{OR}=2.6)$, declining for those living furthest away at 500 meters $(\mathrm{OR}=1.1)$. Sedentary behavior reduction exhibited an inverse decay, where the benefit was lowest for those living adjacent to the greenway at 100 meters $(\mathrm{OR}=0.7)$ and highest for those living in the middle at 300 meters $(\mathrm{OR}=0.5)$. These results suggest that the benefits conferred by the greenway may not be limited to residents living immediately adjacent to the greenway; residents living a few blocks away still benefit in terms of increased MVPA and reduced sedentary behavior. This latter point deserves further investigation to estimate the actual population level benefits of urban greenway interventions. As PA and sedentary behavior are distinct constructs and not the inverse of each other (van der Ploeg, 2017), a reduction of time spent sedentary does not necessarily correspond to an increase in PA, and vice versa. While sedentary behavior and MVPA are part of the same energy expenditure spectrum, data collection using objective rather than self-report means would offer deeper insights into the greenway's effect on PA and sedentary behavior. 


\section{Distance Decay Effect of Greenway}

\section{Moderate-to-Vigorous Physical Activity \\ Proportion achieving $\geq 20$ minutes/day $(n=484)$}

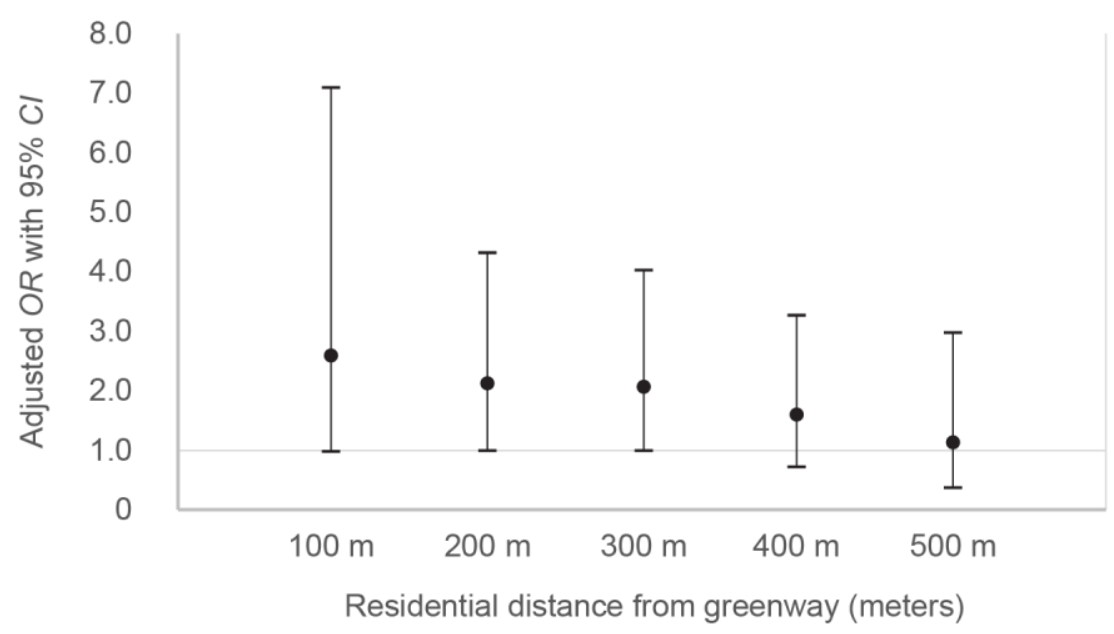

\section{Sedentary Behavior}

Proportion achieving $\geq 9$ hours/day $(n=486)$

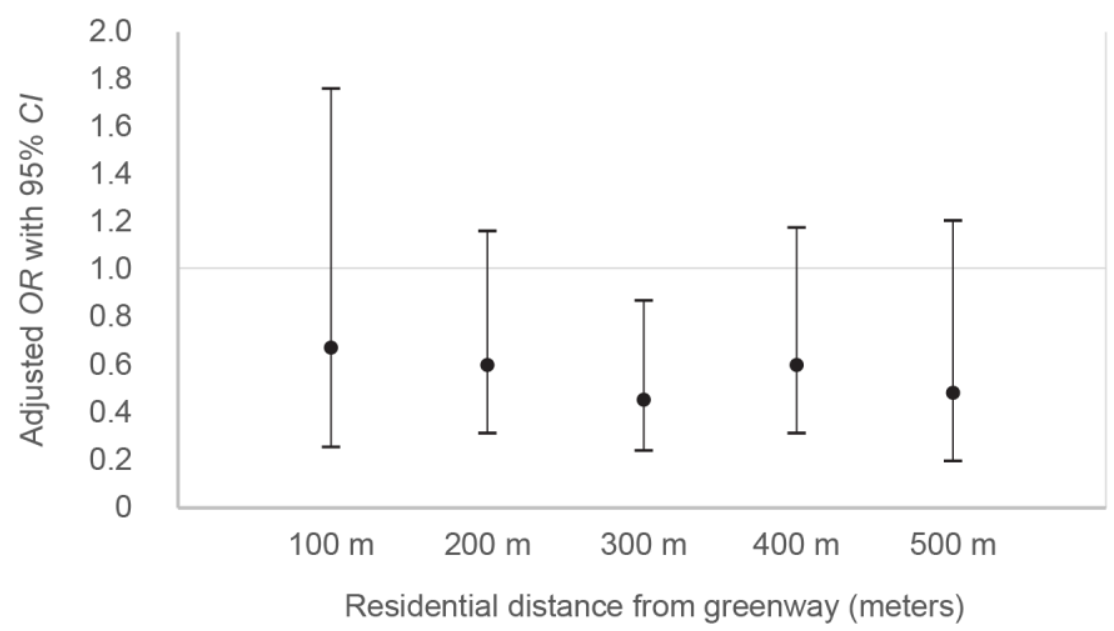

Note: "Greenway exposure" defined as participants living within 300 meters of the greenway. Covariates in final adjusted model: age, gender (male $=1$, female $=0$ ), ethnicity (white $=1$, non-white $=0$ ), employment status (employed full- or part-time $=1$, not employed $=0$ ), educational attainment (completed post-secondary education $=1$, completed secondary education $=0$ ), number of household children, and mean temperature $\left({ }^{\circ} \mathrm{C}\right)$.

Figure 2. Distance gradient effect in mixed-effects logistic models of moderate-to-vigorous physical activity and sedentary behavior 
This paper was accepted by Preventive Medicine. This is an author accepted version.

Given the lack of consensus on appropriate distance thresholds for evaluating urban greenways, future research should account for the role of proximity when evaluating the effect of active transportation facilities on PA outcomes. The selection of a single distance threshold, as conducted in earlier studies, will result in inconsistent reporting of results of observed effects (West and Shores, 2011). Appropriate distance thresholds may depend on the type of active transportation facility and regional contexts under investigation, with different types (off-street path versus a cycle track) and demographic characteristics generating different catchment areas (Larsen et al., 2010). The concept of distance decay with respect to active transportation - here we call "geography of influence", is a well-established concept in geography and ecology (Furuseth and Altman, 1991; Gobster, 1995; Krizek et al., 2007; Larsen et al., 2010; Larsen and El-Geneidy, 2011; Lindsey, 1999). Only one health study has examined this distance decaying effect with respect to walking behavior (Yang and Diez-Roux, 2012). Previous studies of distance decay effect have used larger geographic scales in their analysis, often ranging from 500 meters to several kilometers. Our recommendation aligns with the previous review of built environment studies on PA (Benton et al., 2016; Humphreys et al., 2016) that highlighted the importance of assessing differences in exposure between individuals who reside within the same geographical area in order to minimize confounding bias. To our knowledge, our study is among the first in the public health literature to systematically examine distance decay effect on both PA and sedentary behavior outcomes with respect to an urban greenway using more fined-grained geographic scales (<500 meters). For future studies, it will be useful to explore this concept of "geography of influence" to identify the most optimal thresholds within which infrastructure inventions can have on positive behavioral changes.

\section{Limitations}

This study has a few limitations. First, the MVPA and sedentary behavior outcomes are based on self-reported data. Self-report measures are less reliable than objective methods due to recall bias, response bias, and the inability to capture the absolute level of the measure. Second, our outcome measures represent overall physical activity and sedentary behaviors, which is useful for identifying health relevant thresholds. Future research would need to take into account possible behavioral factors, such as walking, bicycling, and other forms of recreational activities that are relevant to physical activity. Third, our study has limited generalizability as the study area context is characterized by a highly dense urban neighborhood with high street connectivity and good pedestrian infrastructure. The addition of the greenway may have produced a synergistic effect; in other words, the health benefits of a single greenway may not necessarily hold true in less connected neighborhood contexts (Hirsch et al., 2017). However, this also suggests that a dedicated urban greenway can still be beneficial in already pedestrian-friendly neighborhoods. Fourth, the study sample had a high representation of women participants. This may have resulted in a more conservative sample because women are generally less likely to engage in PA compared to men (Azevedo et al., 2007; Miller et al., 2002)

We highlight a few challenges and considerations for future research. Longitudinal research will need to develop strategies to minimize the effect of attrition (the loss of study participants). Attrition can result in a loss of statistical power and may reduce the internal and external validity of the findings as the attrition may be selective to certain demographic characteristics (Young et al., 2006). This creates an inherent trade-off between longer follow-up periods that would 
This paper was accepted by Preventive Medicine. This is an author accepted version.

improve a study's ability to assess behavior change and the risk of further attrition that reduces power and validity. Natural experiments offer a robust way to make causal inferences about the effect of the built environment on PA, but the introduction of biases in the study design can comprise the validity of the findings (Benton et al., 2016). Our study provides a useful methodological contribution through a nuanced assessment of graded exposure that accounts for the effect of distance decay on PA and sedentary behavior. However, our analysis was limited by the lack of more objective data collection methods to fully understand the effects of energy expenditure. While we recommend the use of an activity tracking device, such as accelerometer, it is not suitable for measuring certain activity (e.g. bicycling) and will likely result in increased cost for longitudinal research, which can further constrain the ability to collect an adequate sample size and achieve statistical power.

\section{CONCLUSIONS}

Our study contributes to a small but growing body of causal evidence that the provision of active transportation facilities can lead to PA benefits. Based a natural experiment evaluation of retrofitting an urban greenway, this study found that residents living close to the greenway doubled their odds of completing more than 20 minutes/day of MVPA guidelines and almost halved the odds of being sedentary for more than 9 hours/day after the greenway opened. These benefits showed a declining trend with distance from the greenway suggesting excellent face validity of the results. Results from this study suggest a very favorable return on investment of greenway interventions, considering likely downstream reductions in chronic disease and related healthcare costs from increased physical activity and reduced sedentary time. For public health and urban planning professionals, retrofitting an urban residential neighborhood through modest investments in active transportation facilities can be a successful strategy to promote PA and reducing sedentary behavior in dense urban neighborhoods with relatively low vehicle ownership.

\section{REFERENCES}

Azevedo, M.R., Araújo, C.L.P., Reichert, F.F., Siqueira, F.V., Silva, M.C. da, Hallal, P.C., 2007. Gender differences in leisure-time physical activity. Int. J. Public Health 52, 8. https://doi.org/10.1007/s00038-006-5062-1

Benton, J.S., Anderson, J., Hunter, R.F., French, D.P., 2016. The effect of changing the built environment on physical activity: a quantitative review of the risk of bias in natural experiments. Int. J. Behav. Nutr. Phys. Act. 13, 107. https://doi.org/10.1186/s12966-0160433-3

Boone-Heinonen, J., Gordon-Larsen, P., Guilkey, D.K., Jacobs, D.R., Popkin, B.M., 2011. Environment and physical activity dynamics: The role of residential self-selection. Psychol. Sport Exerc., Mechanisms of Physical Activity Behavior Change 12, 54-60. https://doi.org/10.1016/j.psychsport.2009.09.003

Brown, B.B., Smith, K.R., Tharp, D., Werner, C.M., Tribby, C.P., Miller, H.J., Jensen, W., 2016. A Complete Street Intervention for Walking to Transit, Nontransit Walking, and Bicycling: A Quasi-Experimental Demonstration of Increased Use. J. Phys. Act. Health 13, 1210-1219. https://doi.org/10.1123/jpah.2016-0066

Brownson, R.C., Kelly, C.M., Eyler, A.A., Carnoske, C., Grost, L., Handy, S.L., Maddock, J.E., Pluto, D., Ritacco, B.A., Sallis, J.F., Schmid, T.L., 2008. Environmental and policy 
This paper was accepted by Preventive Medicine. This is an author accepted version.

approaches for promoting physical activity in the United States: a research agenda. J. Phys. Act. Health 5, 488-503.

Buehler, R., Dill, J., 2016. Bikeway Networks: A Review of Effects on Cycling. Transp. Rev. 36, 9-27. https://doi.org/10.1080/01441647.2015.1069908

Buman, M.P., Winkler, E.A.H., Kurka, J.M., Hekler, E.B., Baldwin, C.M., Owen, N., Ainsworth, B.E., Healy, G.N., Gardiner, P.A., 2014. Reallocating Time to Sleep, Sedentary Behaviors, or Active Behaviors: Associations With Cardiovascular Disease Risk Biomarkers, NHANES 2005-2006. Am. J. Epidemiol. 179, 323-334. https://doi.org/10.1093/aje/kwt292

Burchfield, R.A., Fitzhugh, E.C., Bassett, D.R., 2012. The association of trail use with weatherrelated factors on an urban greenway. J. Phys. Act. Health 9, 188-197.

Centers for Disease Control and Prevention (CDC), 2005. Adult participation in recommended levels of physical activity--United States, 2001 and 2003. Morb. Mortal. Wkly. Rep. 54, 1208-1212.

Chastin, S.F.M., Palarea-Albaladejo, J., Dontje, M.L., Skelton, D.A., 2015. Combined Effects of Time Spent in Physical Activity, Sedentary Behaviors and Sleep on Obesity and CardioMetabolic Health Markers: A Novel Compositional Data Analysis Approach. PLOS ONE 10, e0139984. https://doi.org/10.1371/journal.pone.0139984

City of Vancouver, n.d. Protected bicycle lanes [WWW Document]. URL http://vancouver.ca/streets-transportation/protected-bicycle-lanes.aspx (accessed 2.20.18a).

City of Vancouver, n.d. Census local area profiles 2011 [WWW Document]. URL http://data.vancouver.ca/datacatalogue/censusLocalAreaProfiles2011.htm (accessed 2.20.18b).

Colley, R.C., Garriguet, D., Janssen, I., Craig, C.L., Clarke, J., Tremblay, M.S., 2011. Physical activity of Canadian adults: accelerometer results from the 2007 to 2009 Canadian Health Measures Survey. Health Rep. 22, 7.

Coutts, C., 2008. Greenway Accessibility and Physical-Activity Behavior. Environ. Plan. B Plan. Des. 35, 552-563. https://doi.org/10.1068/b3406

Craig, C.S., McCann, J.M., 1978. Item Nonresponse in Mail Surveys: Extent and Correlates. J. Mark. Res. 15, 285-289. https://doi.org/10.2307/3151264

Dill, J., McNeil, N., Broach, J., Ma, L., 2014. Bicycle boulevards and changes in physical activity and active transportation: Findings from a natural experiment. Prev. Med. 69, S74-S78. https://doi.org/10.1016/j.ypmed.2014.10.006

Donaire-Gonzalez, D., Nazelle, A. de, Cole-Hunter, T., Curto, A., Rodriguez, D.A., Mendez, M.A., Garcia-Aymerich, J., Basagaña, X., Ambros, A., Jerrett, M., Nieuwenhuijsen, M.J., 2015. The Added Benefit of Bicycle Commuting on the Regular Amount of Physical Activity Performed. Am. J. Prev. Med. 49, 842-849. https://doi.org/10.1016/j.amepre.2015.03.036

Duncan, S., White, K., Mavoa, S., Stewart, T., Hinckson, E., Schofield, G., 2016. Active Transport, Physical Activity, and Distance Between Home and School in Children and Adolescents. J. Phys. Act. Health 13, 447-453. https://doi.org/10.1123/jpah.2015-0054

Evenson, K.R., Herring, A.H., Huston, S.L., 2005. Evaluating change in physical activity with the building of a multi-use trail. Am. J. Prev. Med. 28, 177-185. https://doi.org/10.1016/j.amepre.2004.10.020 
This paper was accepted by Preventive Medicine. This is an author accepted version.

Fitzhugh, E.C., Bassett, D.R., Evans, M.F., 2010. Urban Trails and Physical Activity: A Natural Experiment. Am. J. Prev. Med. 39, 259-262. https://doi.org/10.1016/j.amepre.2010.05.010

Frank, L.D., Saelens, B.E., Powell, K.E., Chapman, J.E., 2007. Stepping towards causation: Do built environments or neighborhood and travel preferences explain physical activity, driving, and obesity? Soc. Sci. Med. 65, 1898-1914. https://doi.org/10.1016/j.socscimed.2007.05.053

Fraser, S.D.S., Lock, K., 2011. Cycling for transport and public health: a systematic review of the effect of the environment on cycling. Eur. J. Public Health 21, 738-743. https://doi.org/10.1093/eurpub/ckq145

Furuseth, O.J., Altman, R.E., 1991. Who's on the greenway: Socioeconomic, demographic, and locational characteristics of greenway users. Environ. Manage. 15, 329-336. https://doi.org/10.1007/BF02393879

Gobster, P.H., 1995. Perception and use of a metropolitan greenway system for recreation. Landsc. Urban Plan., Greenways 33, 401-413. https://doi.org/10.1016/01692046(94)02031-A

Gordon-Larsen, P., Boone-Heinonen, J., Sidney, S., Sternfeld, B., Jacobs, D.R., Lewis, C.E., 2009. Active commuting and cardiovascular disease risk: the CARDIA study. Arch. Intern. Med. 169, 1216-1223. https://doi.org/10.1001/archinternmed.2009.163

Handy, S.L., Boarnet, M.G., Ewing, R., Killingsworth, R.E., 2002. How the built environment affects physical activity: Views from urban planning. Am. J. Prev. Med. 23, 64-73. https://doi.org/10.1016/S0749-3797(02)00475-0

Heath, G.W., Brownson, R.C., Kruger, J., Miles, R., Powell, K.E., Ramsey, L.T., 2006. The Effectiveness of Urban Design and Land Use and Transport Policies and Practices to Increase Physical Activity: A Systematic Review. J. Phys. Act. Health 3, S55-S76. https://doi.org/10.1123/jpah.3.s1.s55

Hirsch, J.A., Meyer, K.A., Peterson, M., Zhang, L., Rodriguez, D.A., Gordon-Larsen, P., 2017. Municipal investment in off-road trails and changes in bicycle commuting in Minneapolis, Minnesota over 10 years: a longitudinal repeated cross-sectional study. Int. J. Behav. Nutr. Phys. Act. 14. https://doi.org/10.1186/s12966-017-0475-1

Humphreys, D.K., Panter, J., Sahlqvist, S., Goodman, A., Ogilvie, D., 2016. Changing the environment to improve population health: a framework for considering exposure in natural experimental studies. J Epidemiol Community Health 70, 941-946. https://doi.org/10.1136/jech-2015-206381

Hunter, R.F., Christian, H., Veitch, J., Astell-Burt, T., Hipp, J.A., Schipperijn, J., 2015. The impact of interventions to promote physical activity in urban green space: A systematic review and recommendations for future research. Soc. Sci. Med. 124, 246-256. https://doi.org/10.1016/j.socscimed.2014.11.051

Institute of Medicine (US) Committee on Health and Behavior: Research, Practice, and Policy, 2001. Health and Behavior: The Interplay of Biological, Behavioral, and Societal Influences, The National Academies Collection: Reports funded by National Institutes of Health. National Academies Press (US), Washington (DC).

Koster, A., Caserotti, P., Patel, K.V., Matthews, C.E., Berrigan, D., Domelen, D.R.V., Brychta, R.J., Chen, K.Y., Harris, T.B., 2012. Association of Sedentary Time with Mortality Independent of Moderate to Vigorous Physical Activity. PLOS ONE 7, e37696. https://doi.org/10.1371/journal.pone.0037696 
This paper was accepted by Preventive Medicine. This is an author accepted version.

Krizek, K.J., El-Geneidy, A., Thompson, K., 2007. A detailed analysis of how an urban trail system affects cyclists' travel. Transportation 34, 611-624.

https://doi.org/10.1007/s11116-007-9130-z

Larsen, J., El-Geneidy, A., 2011. A travel behavior analysis of urban cycling facilities in Montréal, Canada. Transp. Res. Part Transp. Environ. 16, 172-177. https://doi.org/10.1016/j.trd.2010.07.011

Larsen, J., El-Geneidy, A., Yasmin, F., 2010. Beyond the Quarter Mile: Re-examining Travel Distances by Active Transportation. Can. J. Urban Res. 19, 70-88.

Lindsey, G., 1999. Use of urban greenways: insights from Indianapolis. Landsc. Urban Plan. 45, 145-157. https://doi.org/10.1016/S0169-2046(99)00023-7

Merom, D., Bauman, A., Vita, P., Close, G., 2003. An environmental intervention to promote walking and cycling - the impact of a newly constructed Rail Trail in Western Sydney. Prev. Med. 36, 235-242. https://doi.org/10.1016/S0091-7435(02)00025-7

Miller, Y.D., Trost, S.G., Brown, W.J., 2002. Mediators of physical activity behavior change among women with young children. Am. J. Prev. Med., INNOVATIVE APPROACHES UNDERSTANDING AND INFLUENCING PHYSICAL ACTIVITY 23, 98-103. https://doi.org/10.1016/S0749-3797(02)00484-1

Mokhtarian, P.L., Cao, X., 2008. Examining the impacts of residential self-selection on travel behavior: A focus on methodologies. Transp. Res. Part B Methodol., A Tribute to the Career of Frank Koppelman 42, 204-228. https://doi.org/10.1016/j.trb.2007.07.006

Mytton, O.T., Panter, J., Ogilvie, D., 2016. Longitudinal associations of active commuting with body mass index. Prev. Med. 90, 1-7. https://doi.org/10.1016/j.ypmed.2016.06.014

National Task Force on the Prevention and Treatment of Obesity, 2000. Overweight, obesity, and health risk. Arch. Intern. Med. 160, 898-904.

Ngo, V.D., Frank, L.D., Bigazzi, A.Y., 2018. Effects of new urban greenways on transportation energy use and greenhouse gas emissions: A longitudinal study from Vancouver, Canada. Transp. Res. Part Transp. Environ. 62, 715-725.

Office of the Surgeon General (US), 2001. The Surgeon General's Call To Action To Prevent and Decrease Overweight and Obesity, Publications and Reports of the Surgeon General. Office of the Surgeon General (US), Rockville (MD).

Ottoni, C.A., Sims-Gould, J., Winters, M., Heijnen, M., McKay, H.A., 2016. "Benches become like porches": Built and social environment influences on older adults' experiences of mobility and well-being. Soc. Sci. Med. 169, 33-41. https://doi.org/10.1016/j.socscimed.2016.08.044

Pucher, J., Dill, J., Handy, S., 2010. Infrastructure, programs, and policies to increase bicycling: An international review. Prev. Med. 50, S106-S125. https://doi.org/10.1016/j.ypmed.2009.07.028

Sahlqvist, S., Song, Y., Ogilvie, D., 2012. Is active travel associated with greater physical activity? The contribution of commuting and non-commuting active travel to total physical activity in adults. Prev. Med. 55, 206-211. https://doi.org/10.1016/j.ypmed.2012.06.028

Sallis, J.F., Cerin, E., Conway, T.L., Adams, M.A., Frank, L.D., Pratt, M., Salvo, D., Schipperijn, J., Smith, G., Cain, K.L., Davey, R., Kerr, J., Lai, P.-C., Mitáš, J., Reis, R., Sarmiento, O.L., Schofield, G., Troelsen, J., Dyck, D.V., Bourdeaudhuij, I.D., Owen, N., 2016. Physical activity in relation to urban environments in 14 cities worldwide: a cross- 
This paper was accepted by Preventive Medicine. This is an author accepted version.

sectional study. The Lancet 387, 2207-2217. https://doi.org/10.1016/S01406736(15)01284-2

Sallis, J.F., Glanz, K., 2006. The role of built environments in physical activity, eating, and obesity in childhood. Future Child. 16, 89-108.

Sallis, J.F., Kerr, J., 2006. Physical activity and the built environment. Pres. Counc. Phys. Fit. Sports Res. Dig. 7.

Sallis, J.F., Story, M., Lou, D., 2009. Study Designs and Analytic Strategies for Environmental and Policy Research on Obesity, Physical Activity, and Diet. Am. J. Prev. Med. 36, S72S77. https://doi.org/10.1016/j.amepre.2008.10.006

Saneinejad, S., Roorda, M.J., Kennedy, C., 2012. Modelling the impact of weather conditions on active transportation travel behaviour. Transp. Res. Part Transp. Environ. 17, 129-137. https://doi.org/10.1016/j.trd.2011.09.005

Ting, Y., Curtin, Richard, Jans, Matthew, 2010. Trends in Income Nonresponse Over Two Decades. J. Off. Stat. 26, 145-164.

Twisk, J.W.R., 2013. Applied Longitudinal Data Analysis for Epidemiology: A Practical Guide [WWW Document]. Camb. Core. https://doi.org/10.1017/CBO9781139342834

Warburton, D.E.R., Nicol, C.W., Bredin, S.S.D., 2006. Health benefits of physical activity: the evidence. Can. Med. Assoc. J. 174, 801-809. https://doi.org/10.1503/cmaj.051351

Waxman, A., World Health Assembly, 2004. WHO global strategy on diet, physical activity and health. Food Nutr. Bull. 25, 292-302. https://doi.org/10.1177/156482650402500310

West, S.T., Shores, K.A., 2015. Does building a greenway promote physical activity among proximate residents? J. Phys. Act. Health 12, 52-57. https://doi.org/10.1123/jpah.20120411

West, S.T., Shores, K.A., 2011. The impacts of building a greenway on proximate residents' physical activity. J. Phys. Act. Health 8, 1092-1097.

Winters, M., Teschke, K., 2010. Route Preferences among Adults in the near Market for Bicycling: Findings of the Cycling in Cities Study. Am. J. Health Promot. 25, 40-47. https://doi.org/10.4278/ajhp.081006-QUAN-236

Yang, Y., Diez-Roux, A.V., 2012. Walking Distance by Trip Purpose and Population Subgroups. Am. J. Prev. Med. 43, 11-19. https://doi.org/10.1016/j.amepre.2012.03.015

Young, A.F., Powers, J.R., Bell, S.L., 2006. Attrition in longitudinal studies: who do you lose? Aust. N. Z. J. Public Health 30, 353-361. https://doi.org/10.1111/j.1467842X.2006.tb00849.x 
This paper was accepted by Preventive Medicine. This is an author accepted version.

\section{Supplemental Materials}

Table S1. Sensitivity analysis of mixed-effect logistic models using different MVPA and sedentary behavior time thresholds

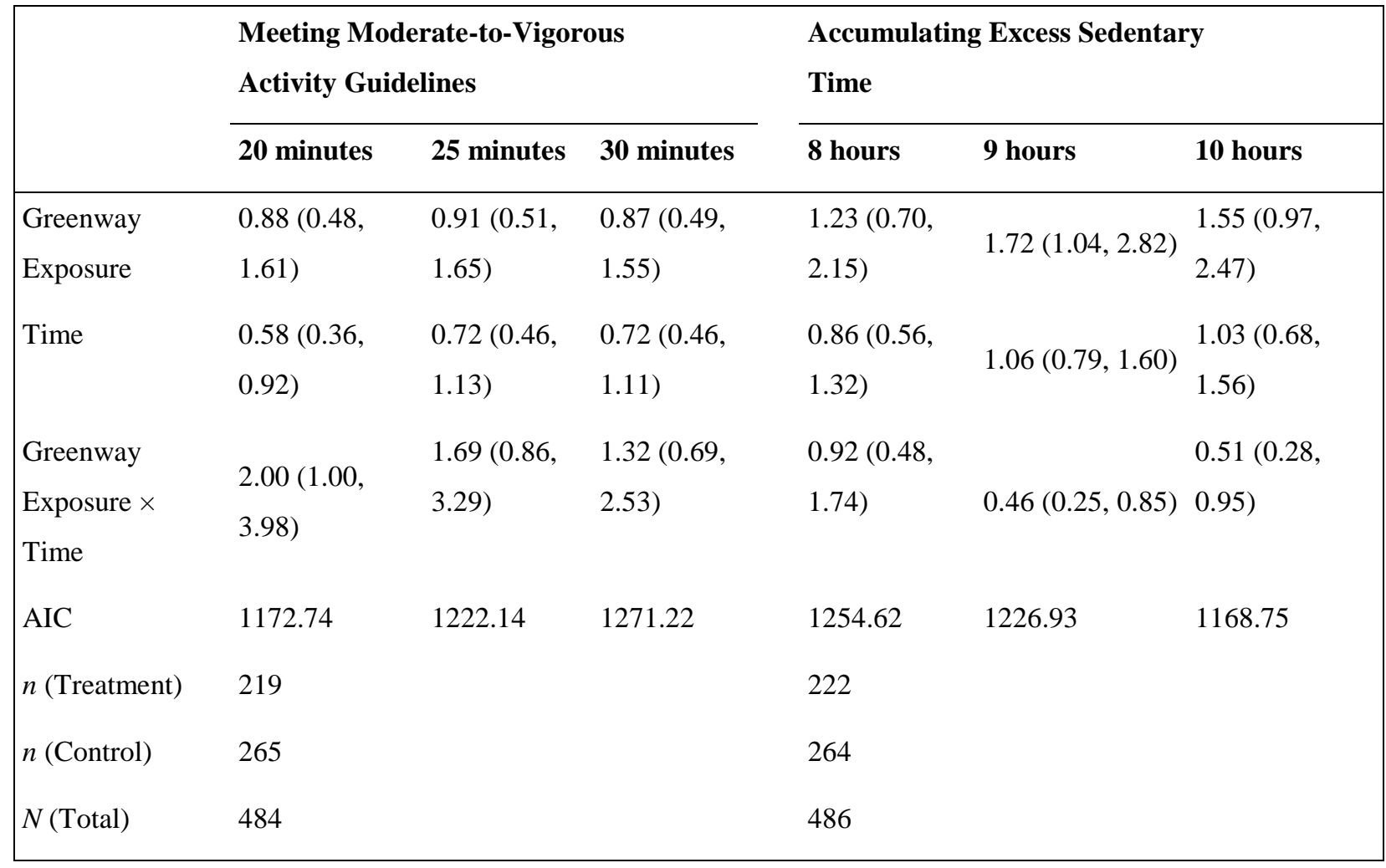

Note: Odds ratio $(95 \% \mathrm{CI})$. "Greenway exposure" defined as participants living within 300 meters of the greenway. Covariates in final adjusted model: age, gender $($ male $=1$, female $=0$ ), ethnicity (white $=1$, non-white $=0$ ), employment status (employed full- or part-time $=1$, not employed $=0$ ), educational attainment (completed post-secondary education $=1$, completed secondary education $=0)$, number of household children, and mean temperature $\left({ }^{\circ} \mathrm{C}\right)$. $p<0.05(*), p<0.01(* *), p<0.001(* * *)$ 